\title{
Design and Development of a Low Cost Grain Flour Blender
}

\author{
B. D. M. P. Bandara Dissanayake, H. S. Jayewardene and B. M. K. S. Thilakarathne
}

\begin{abstract}
One of the major solutions to reduce the consumption of wheat flour in the country is to introduce flour mixtures blended with rice flour and other locally produced grain flour to the market and flour based food processors, since it has a great demand even now. Blending equipment are essential to produce flour mixtures with uniformly distributed particles. Flour blending machines are available in the international market, but they are very expensive and those are not at an affordable price to purchase even for medium scale flour producers. Therefore, a low cost grain flour blender was designed and developed to introduce for flour producers. Developed grain flour blender was tested by blending rice flour with wheat flour to the ratio of 3:7 which is generally used for preparing bread. It was found that the minimum blending time required for giving a uniform mixture was 3 minutes when the equipment was operated at $51 \mathrm{rpm}$. Capacity of the blender was $50 \mathrm{~kg}$ per batch and it was operated by a $3 \mathrm{hp}$ electric motor. When the developed flour blender is compared with the available blending machines in the international market with same capacity, it was found that the developed flour blender reduces the blending time and the initial cost of the machine is reduced by 5 times while the flour blending cost is reduced by $25 \%$.
\end{abstract}

Keywords: Rice flour, grains, mixtures, processors, blending machine

\section{Introduction}

Increasing the availability of rice flour and other locally produced grain flour by developing flour processing industry in the country and popularizing food prepared with theses flour among the people, consumption of wheat flour could be reduced to a remarkable level. One of the major solutions to reduce consumption of wheat flour further is introducing flour mixtures blended with rice flour and other locally produced grain flour to the market and flour based food processors, since it has a great demand even now. According to the research findings, any wheat flour based food item can be prepared adding $20 \%$ rice flour by following the same manufacturing methods. Therefore blended rice flour can be introduced to bakeries and other flour based food industries and also to the wheat flour consuming people in the upcountry to make their favourite food item called roti. Some bakery owners have now started to prepare bakery products such as bread, biscuits and cake with rice flour or wheat flour blended rice flour. In this regard, the problem faced by the bakery owners and other flour based food manufactures is finding suitable flour mixtures. However, a few flour processors in the country have introduced blended flour (ex: rice flour with wheat flour, rice flour with finger millet flour etc.) to the market and there is a good demand for their products. Blending of flours is basically done by these processors manually with the help of spoons and plastic vessels. This method being time consuming, laborious and inefficient, the final product is not uniform in composition. Flour blending machines are available in the international market, but they are very expensive and those are not affordable even for medium scale flour producers. Therefore, a low cost grain flour blender was designed and developed under this project to introduce for flour producers. Performance of the developed equipment was evaluated.

\section{Literature Review}

The food industry produces a wide variety of particulate mixtures which combine a wide variety of ingredients such as sugars, flour, dairy products, salt, dried cereals, vegetables and fruits. Mixing of these particulate ingredients involves the movement of the

Eng. B.D.M.P. Bandara Dissanayake, AMIE (Sri Lanka), B.Sc. Eng. (Mech. Eng.) (Peradeniya), M. Eng. (PFE) (India), Mechanical Engineer, Institute of Post Harvest Technology, Anuradhapura.

H.S. Jayewardene, B.Sc. (Applied Sci.) (Sabaragamuwa), M Phil (Food Sci. \& Tech) (Jayewardenepura), Research Officer, Institute of Post Harvest Technology, Anuradhapura.

B.M.K.S. Thilakerathne, B.Sc. Sp. (Agric. Food Sci. Tech.) (Peradeniya), M.Sc. (Food Sci. \& Tech.)(Jayewardenepura), Ph.D. (Postharvest Tech. Horticulture)(India), Director, Institute of Post Harvest Technology, Anuradhapura. 
ingredients throughout each other, in an effort to produce a uniform distribution of each component throughout the mix [1].

Mixing is defined as a shuffling type unit operation process involving both large and small particle groups and even individual particles. Mixing is an energy consuming process which produces a random distribution of particles. It is dependent on the probability that an event happens in a given time and once the desired mixing has been attained, it is essential that the particles in the mix cease movement so that the system may exist in a state of static equilibrium without segregation. Some of the parameters affecting efficient mixing are:

a) Particle parameters like particle size, particle shape, size distribution, particle density, cohesively, hygroscopicity and hardness.

b) Type of mixer: Speed, time, batch volume, and movement

c) Segregation tendency of individual component based on density difference.

An ideal mixer should be capable of producing a complete blend in reasonable time without damaging the product. Additionally, it should be dust-tight, require less maintenance and low energy, capable of easy discharge, and cleaned easily. All these properties cannot be found in a single mixer. However, a logical selection of a mixer can be done based on powder characteristics of the constituents of the mixture, quality requirements of the product and process requirements \& limitations. And also, the points needed to be considered, to ensure overall success of a mixing process, are flexibility to cope with a variable batch size, transportation of mixing vessel between operations (like loading, mixing, packaging), easy access for sampling, separation of processed materials, requirement of frequent cleaning and nature of the mixing surface. The effectiveness of a mixer depends on the powders to be mixed, the time of mixing, number of rotations of the mixer etc [4].

The cost of the flour blender of with a capacity of $50 \mathrm{~kg} / \mathrm{batch}$ available in the international is Rs.550,000. Blending time is about 10-15 $\mathrm{min}$. Flour blending cost is about Rs. 1.29 per kg.

\section{Design}

Figure 1 shows the flour blender, of which the volumetric capacity of the equipment is 178 litres. It consists of a hopper, closing door, cylindrical mixing drum, mixing blade assembly, power transmission assembly, discharging plate and frame. A cylindrical drum of $600 \mathrm{~mm}$ diameter and $600 \mathrm{~mm}$ length was fabricated using 18 BWG (1.5 mm) SS-304 sheets and used as the flour mixing chamber. A hopper with a cross sectional dimensions of 225 $\mathrm{mm} \times 600 \mathrm{~mm}$ and $25 \mathrm{~mm}$ height is fitted to the cylindrical drum. The hopper was fabricated using 18 BWG $(1.5 \mathrm{~mm})$ SS-304 sheets. A rectangular door having a cross section of 275 $\mathrm{mm} \times 600 \mathrm{~mm}$, fabricated using the same material was hinged to the hopper and it was used as the closing door. Three pieces of SS-304 pipes having $12.5 \mathrm{~mm}$ diameter and $100 \mathrm{~mm}$ length were welded to the other side of the closing door and door can be locked by fastening a $6 \mathrm{~mm}$ SS rod through the three pieces of pipes.

A hollow shaft was fixed at the centre axis of the cylindrical drum and three SS-304 flat blades having a cross section of $50 \mathrm{~mm} \times 5 \mathrm{~mm}$ and $575 \mathrm{~mm}$ length were bolted to the arms welded to the hollow shaft. Blades were fixed with an angular distance of $120^{\circ}$ between each. The position of the blades can be changed. Another set of three blades having same dimensions as described above were bolted to the arms welded to the inner periphery of the cylindrical drum. Each blade was bolted to three arms. The cylindrical mixing drum containing blades, hopper and closing door was fixed to rigid frame by using a $25 \mathrm{~mm}$ diameter mild steel shaft running through the hollow centre axis shaft and two pillow block bearings fixed at the ends of the shaft. Two $6 \mathrm{~mm}$ diameter SS rods were attached to the closing door as the controller for the door opening. Closing door can be kept at a place by fixing the rods by a locking mechanism fixed to the cylindrical drum. Discharging plate was fabricated using 18 BWG (1.5 mm) SS-304 sheets and fixed at the bottom of the cylindrical drum. Discharging plate has an angle of $40^{\circ}$ to the horizontal. The equipment is mounted on the rigid frame made of mild steel angles. The rigid frame was fabricated using $37.5 \mathrm{~mm} \times 37.5$ $\mathrm{mm}$ angles having $5.5 \mathrm{~mm}$ thickness. The Frame has overall dimensions of $600 \mathrm{~mm} \times 725$ $\mathrm{mm} \times 1100 \mathrm{~mm}$. Power required to rotate the mixer was given by a $3 \mathrm{hp}$, three phase electrical motor fixed to the frame. Rotational speed of the motor is $1440 \mathrm{rpm}$. A rotational speed of 51 rpm was given to the cylindrical mixing drum by reducing the motor speed with two belt drive systems having speed reduction ratios of 
3:14 and 3:18 as shown in the figure. A cast iron pulley having $75 \mathrm{~mm}$ diameter was fixed to the motor shaft and power was transferred to 350 $\mathrm{mm}$ diameter cast iron pulley fixed on an intermediate shaft. The Intermediate shaft made of mild steel and having $25 \mathrm{~mm}$ diameter was fixed to the frame at a position $250 \mathrm{~mm}$ above the motor. Power from the intermediate shaft to the cylindrical drum mixer shaft was transmitted by a $\mathrm{V}$ belt using a $75 \mathrm{~mm}$ diameter cast iron pulley fixed to the intermediate shaft and $450 \mathrm{~mm}$ diameter cast iron pulley fixed to the mixer drum shaft. The machine was fixed on the ground using bolts to provide stability when it is in operation.

In operation, mixing drum was held in an upright position and flour to be mixed were put to the machine. Then the door was closed and locked. Power supply was switched on and mixing was done for a few minutes. Then power was switched off. The speed of the machine was gradually reduced before coming to the stationary position. were selected. Size of the blades were selected according to the inside dimension of the cylindrical mixing drum. Materials were selected for a hygienic design. Various components of the equipment were designed with the help of the standard relations in a Text Book of Machine Design [2]. Power requirement for blender was calculated by using the relevant formula [3]. Considering nearest available values of the material and also the available facilities for fabrication, the dimension of the components were selected. And also, one sheet of $8^{\prime} \times 4^{\prime}$ SS-18 BWG (1.5 $\mathrm{mm}$ ) was used totally for fabrication to reduce the cost of the machine while satisfying the design requirements.

\subsection{Power}

Power requirement for the operation of the developed equipment was calculated by using the following expression [3].

Power required, $\mathrm{P}=\frac{M \times L \times g}{T}$ Watt

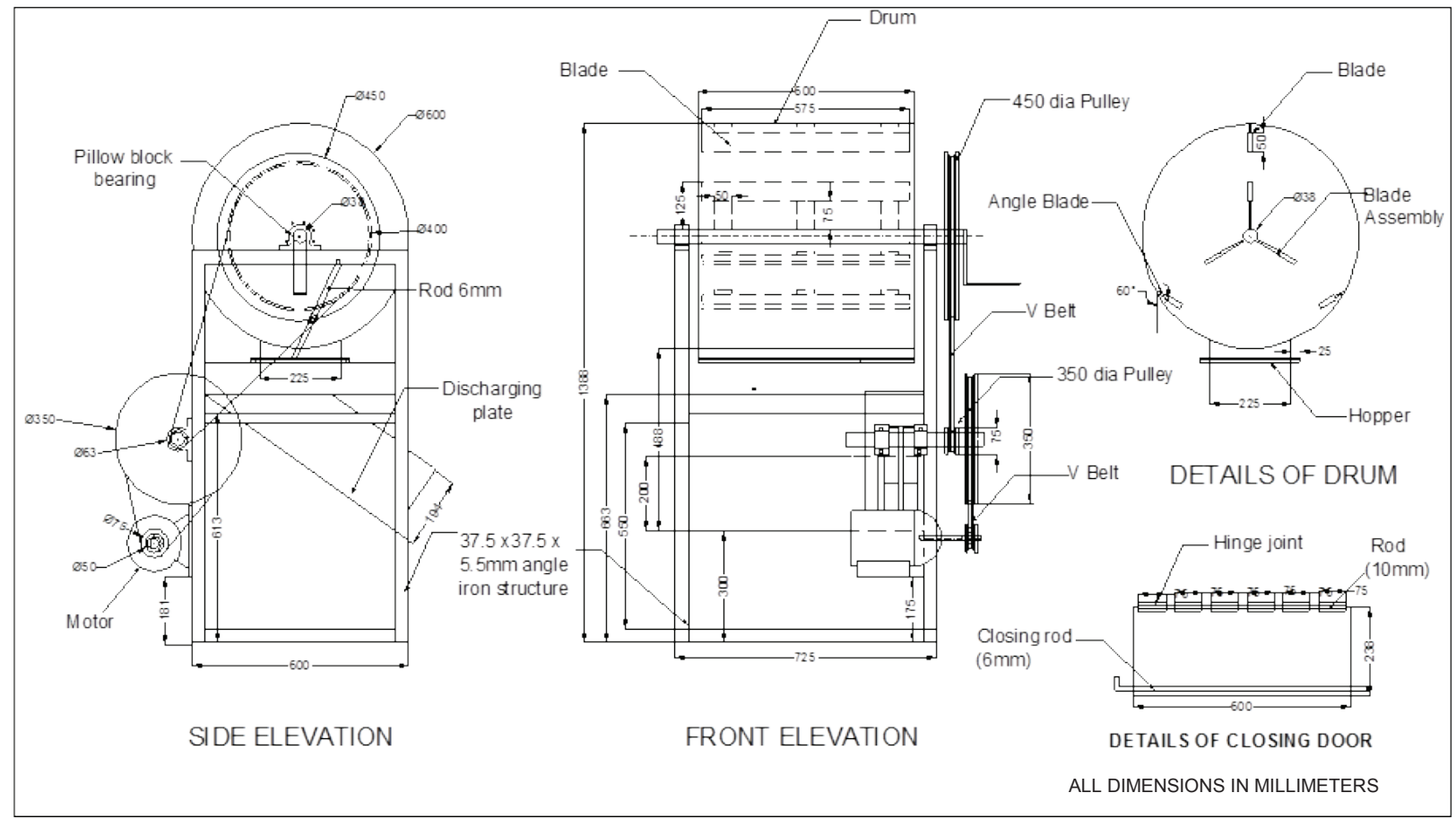

Figure 1- Drawing of Grain Flour Blending Equipment

By turning the mixing drum to a position that the hopper comes to the bottom and then the door was unlocked and opened slowly and fixed at a position with the help of door controlling devices. Then flour mixture was discharged from the machine.

\subsection{Design Description:}

Considering the maximum space required for a batch size of grain flour under design conditions, dimensions of casing and hopper
Where,

$\mathrm{M}=$ Food quantity, $\mathrm{kg}$

$\mathrm{L}=$ Circumferential distance of force application pulley, $\mathrm{m}$

$\mathrm{T}=$ operation time, $\mathrm{s}$

$\mathrm{g}=$ Gravitational acceleration $\left(\mathrm{m} / \mathrm{s}^{2}\right)$ 
The operating capacity of the machine was 50 $\mathrm{kg}$ per batch. However in the designing process, it was assumed that the maximum food capacity was 1.5 times the operating capacity and power requirement was calculated. Preliminary tests were conducted to find the required rotational speed (rpm) for mixing and it was found that the required rotational speed for mixing was about $50 \mathrm{rpm}$. Hence the pulleys were selected to achieve this rotational speed (rpm) for the mixing machine.

\section{Substituting values}

$\mathrm{M}=50 \mathrm{~kg}, \mathrm{~L}=2 \Pi \times 225 \mathrm{~mm}, \mathrm{~N}=1 \mathrm{rev} / 0.83 \mathrm{~s}$ in above equation,

Power requirement $\mathrm{P}$,

$$
\mathrm{P}=\frac{50 \times \pi \times \frac{225}{1000} \times 9.81}{0.83} \mathrm{~W}
$$

$\mathrm{P}=1253.18 \mathrm{~W}$

Taking the efficiencies of each bearing unit as $90 \%$ and the efficiencies of the belt drive systems as $90 \%$ for each and since the machine consists of two bearing units and two belts drive systems;

Total power requirement can be calculated as

W

$$
=\frac{1253.18}{0.9 \times 0.9 \times 0.9 \times 0.9}
$$

$$
\begin{aligned}
& =1910.04 \mathrm{~W} \\
\text { or } & =2.56 \mathrm{hp}
\end{aligned}
$$

Considering the availability, 3hp motor was selected.

\subsection{Design of the belt drive system 1 (Motor to intermediate shaft) [2]}

Rotational speed of intermediate shaft pulley

$$
\frac{N_{1}}{N_{2}}=\frac{d_{2}}{d_{1}} \quad \text { i.e. } \quad N_{2}=\frac{d_{1} \times N_{1}}{d_{2}}
$$

Where,

$\mathrm{N}_{1}=$ Rotational speed of the motor shaft (rpm)

$\mathrm{N}_{2}=$ Rotational speed of the intermediate shaft (rpm) $\mathrm{d}_{1}=$ Diameter of the motor pulley

$\mathrm{d}_{2}=$ Diameter of the intermediate shaft pulley

Taking $\mathrm{d}_{2}=350 \mathrm{~mm}, \mathrm{~N}_{1}=1440 \mathrm{rpm}, \mathrm{d}_{1}=75 \mathrm{~mm}$

$$
\begin{aligned}
& N_{2}=\frac{1440 \times 75}{350}=308.57 \mathrm{rpm}, \\
& \operatorname{Sin} \alpha=\frac{r_{2}-r_{1}}{x}=\frac{d_{2}-d_{1}}{2 \times x}
\end{aligned}
$$

Where,

$\mathrm{r}_{1}=$ Radius of the motor pulley

$\mathrm{r}_{2}=$ Radius of the intermediate shaft pulley

$x=$ Distance between centres of the pulleys

Taking, $\mathrm{x}=300 \mathrm{~mm}, \quad \operatorname{Sin} \alpha=\frac{350-75}{2 \times 300}=0.458$

or $\alpha=27.28^{\circ}$

Angle of contact

$$
\begin{gathered}
\theta=180-2 \alpha=180^{\circ}-2 \times 27.28^{\circ}=125.44^{\circ} \\
=125.44 \times \pi / 180=2.19 \mathrm{rad}
\end{gathered}
$$

Let $\mathrm{T}_{1}=$ Tension on the tight side of the belt

$$
\mathrm{T}_{2}=\text { Tension on the slack side of the belt }
$$

Assuming the groove angle of the pulley, $2 \beta=35^{\circ} \quad$ or $\quad \beta=17.5^{\circ}$

We know that,

$$
2.3 \log \left(\frac{T_{1}}{T_{2}}\right)=\mu \cdot \theta \cdot \operatorname{cosec} \beta
$$

Where, $\mu=$ Coefficient of Friction between belt and pulleys

Taking $\mu=0.28$

$2.3 \log \left(\frac{T_{1}}{T_{2}}\right)=0.28 \times 2.19 \times \operatorname{cosec} 17.5^{\circ}=1.70$

After simplifying, $\frac{T_{1}}{T_{2}}=7.70$

Velocity of the belt,

$v=\frac{\pi d_{1} N_{1}}{60}=\frac{\pi \times 0.075 \times 1440}{60}=5.65 \mathrm{~m} / \mathrm{sec}$

Weight of the belt per meter length,

$$
w=\text { Area } \times \text { Length } \times \text { Density }
$$

Taking, Area of the belt $=1.98 \mathrm{~cm}^{2}$ and density of the belt material $=0.001 \mathrm{~kg} / \mathrm{cm}^{3}$ 


$$
w=1.98 \times 100 \times 0.001=0.198 \mathrm{~kg} / \mathrm{m}
$$

Centrifugal tension in the belt

$$
T_{C}=\frac{w}{g} \times v^{2}=\frac{0.198}{9.81} \times 5.65^{2}=0.64 k g f
$$

And maximum tension in the belt

$$
T=\text { stress } \times \text { area }=f . a
$$

Taking, $f=20 \mathrm{~kg} / \mathrm{cm}^{2}$ and substituting,

$$
T=20 \times 1.98=39.6 \mathrm{~kg} f
$$

$\therefore$ Tension on the tight side of the belt

$$
\begin{aligned}
& T_{1}=T-T_{C}=39.6-0.64=38.96 \mathrm{~kg} f \\
& T_{2}=\frac{T_{1}}{7.70}=\frac{38.96}{7.70}=5.06 \mathrm{kgf}
\end{aligned}
$$

Horse power transmitted per belt $=\frac{\left(T_{1}-T_{2}\right) v}{75}$

$$
=\frac{(38.96-5.06) \times 5.65}{75}=2.55 h . p \text {. }
$$

Since the over load factor is 1.5 , therefore the belt is to be designed for $1.5 \times 3=4.5 \mathrm{~h} . \mathrm{p}$.

Therefore,

Number of belt required $=\frac{\text { Designed horse power }}{\text { Horse power per belt }}$

$$
=\frac{4.5}{2.55}=1.76 \text { say } 2
$$

\subsection{Design of intermediate shaft [2]}

Let $\quad \mathrm{D}=$ Diameter of the shaft

The torque transmitted by the driven pulley shaft

$$
\begin{aligned}
T & =\frac{\text { Designed h.p. } \times 4500}{2 \pi N_{2}} \\
& =\frac{4.5 \times 4500}{2 \pi \times 560}=5.76 \mathrm{kgf}-\mathrm{m}=576 \mathrm{kgf}-\mathrm{cm}
\end{aligned}
$$

Since the overhang of the pulley is $10 \mathrm{~cm}$, therefore

Bending moment on the shaft due to the belt tension,

$$
\begin{gathered}
M=\left(T 1+T_{2}+2 T_{c}\right) \times 10 \times 3 \\
(\because \text { No. of belts }=3)
\end{gathered}
$$

$M=(39.32+2.42+2 \times 0.28) \times 10 \times 3$

$M=1269 \mathrm{kgf}-\mathrm{cm}$

$\therefore$ Equivalent twisting moment

$$
\begin{aligned}
T_{e} & =\sqrt{T^{2}+M^{2}}=\sqrt{576^{2}+1269^{2}} \\
& =1393.61 \mathrm{kgf.cm}
\end{aligned}
$$

We also known that equivalent twisting moment

$$
T_{e}=\frac{\pi}{16} \times f_{s} \times D^{3}
$$

Where $f_{s}=$ Permissible shear stress

Taking $f_{S}=62 \mathrm{~N} / \mathrm{mm}^{2}=6200 \mathrm{kgf} / \mathrm{cm}^{2}$

$$
\begin{aligned}
1393.61 & =\frac{\pi}{16} \times 6200 \times D^{3} \\
D & =1.05 \mathrm{~cm} \text { or } 10.5 \mathrm{~mm}
\end{aligned}
$$

Considering the availability of material 12.5 mm shaft was selected.

\subsection{Design of the belt drive system 2} (Intermediate shaft to mixer shaft) and mixer shaft [2]

Rotational speed of mixer shaft pulley

$$
\begin{aligned}
& \frac{N_{4}}{N_{3}}=\frac{d_{3}}{d_{4}} \\
& N_{4}=\frac{d_{3} \times N_{3}}{d_{4}}
\end{aligned}
$$

Where,

$\mathrm{N}_{3}=$ Rotational speed of the intermediate shaft (rpm) - (Note: $\mathrm{N}_{3}=\mathrm{N}_{2}$ )

$\mathrm{N}_{4}=$ Rotational speed of the mixer shaft (rpm)

$\mathrm{d}_{3}=$ Diameter of the intermediate shaft pulley for belt drive 2

$\mathrm{d}_{4}=$ Diameter of the mixer shaft pulley

Taking $\mathrm{d}_{3}=75 \mathrm{~mm}, \mathrm{~N}_{3}=308.57 \mathrm{rpm}, \mathrm{d}_{4}=$ $450 \mathrm{~mm}$

$$
N_{4}=\frac{308.57 \times 75}{450}=51.43 \mathrm{rpm},
$$




$$
\operatorname{Sin} \alpha=\frac{r_{4}-r_{3}}{x_{1}}=\frac{d_{4}-d_{3}}{2 \times x_{1}}
$$

Where, $r_{3}=$ Radius of the intermediate shaft pulley for belt drive system 2

$\mathrm{r}_{4}=$ Radius of the mixer shaft pulley

$\mathrm{x}_{1}=$ Distance between centres of the pulleys

Taking, $\mathrm{x}_{1}=650 \mathrm{~mm}$,

$\operatorname{Sin} \alpha=\frac{450-75}{2 \times 650}=0.2285$ or $\alpha==16.77^{\circ}$

Angle of contact

$$
\begin{aligned}
\theta & =180-2 \alpha=180^{\circ}-2 \times 16.77^{\circ}=146.46^{\circ} \\
& =146.46 \times \pi / 180=2.56 \mathrm{rad}
\end{aligned}
$$

In designing this belt drive system, the same procedure used in design of the belt drive system 1 was followed. Belts were designed for high quality; high capacity $\mathrm{D}$ type $\mathrm{V}$ belt and following data values were used.

$\beta=20^{\circ}$, Area of the belt $=4.75 \mathrm{~cm}^{2}$, density of the belt material $=1.2 \mathrm{~g} / \mathrm{cm}^{3}$, allowable tensile stress $f=30 \mathrm{kgf} / \mathrm{cm}^{2}$ and overhang of the pulley is $10 \mathrm{~cm}$. Substituting theses values in the same equations used in design of the belt drive system 1 and simplifying, it was given, number of belt required as 2 and diameter of the shaft of mixer as $13.8 \mathrm{~mm}$. Considering the availability $25 \mathrm{~mm}$ was selected.

\subsection{Cross sectional dimensions of the blade arm [2]}

The cross section of the arm is obtained by considering the arm as cantilever i.e., fixed at the shaft end and carrying a concentrated load at the blade end. The length of the cantilever is taken equal to the distance from shaft to the centre of the blades. It is further assumed that at any given time, power is transmitted from shaft to the flour load of the blender through only 2 blades. Since one blade has 3 arms, total number of arms under consideration is 6 .

Tangential load per arm is given by the following equation [2]

$$
W_{T}=\frac{T}{R \times n}=\frac{T}{R \times n}
$$

Where,

$\mathrm{T}=$ Torque Transmitted

$\mathrm{R}=$ Radius of blades rotating circle $\mathrm{n}=$ Number of Arms,

So, Maximum bending moment on the arm at the shaft end

$$
M=\frac{T}{R \times n} \times R=\frac{T}{n}
$$

Section modulus of Arm

$$
Z=\frac{1}{6} t_{A} \cdot B_{A}{ }^{2}
$$

Where,

$t_{\mathrm{A}}=$ thickness of the arm

$\mathrm{B}_{\mathrm{A}}=$ width of the arm

Since $f_{b}=\frac{M}{Z}$, substituting $M \& Z$, we get

$$
f_{b}=\frac{T}{n} \times \frac{6}{t_{A} \times B_{A}{ }^{2}}=\frac{6 T}{n \times t_{A} \times B_{A}{ }^{2}}
$$

The torque transmitted by the driven pulley shaft

$$
T=\frac{\text { Designed } h \cdot p \cdot \times 4500}{2 \pi N_{4}}
$$

But from previous calculation $\mathrm{N}_{4}=51.43 \mathrm{rpm}$, so

$$
T=\frac{4.5 \times 4500}{2 \pi \times 51.43}=63.19 \mathrm{kgf} . \mathrm{m}
$$

$$
=62670 \mathrm{kgf} . \mathrm{mm}=614792.7 \mathrm{~N} . \mathrm{mm}
$$

For arm material $\mathrm{f}_{\mathrm{b}}=70 \mathrm{~N} / \mathrm{mm}^{2}$,

Taking; $\mathrm{n}=6, \mathrm{R}=100 \mathrm{~mm}$ and assuming $\mathrm{B}_{\mathrm{A}}=10 \mathrm{t}_{\mathrm{A}}$

Substituting these values in equation (c)

$$
70=\frac{6 \times 614792.7}{6 \times t_{A} \times 100 \times t_{A}^{2}}
$$

Simplifying, $\quad t_{\mathrm{A}}=4.44 \mathrm{~mm}$

Considering the availability $t_{A}$ was taken as $5 \mathrm{~mm}$

Therefore, $\mathrm{B}_{\mathrm{A}}=50 \mathrm{~mm}$.

\subsection{Frame}

The equipment is mounted on a rigid frame made of mild steel angles. The rectangular dimensions of the frame are selected according 
to the dimensions of the cylindrical drum and considering easy operation of the equipment. The thickness of the frame materials was calculated according to the load acting on frame, such as weight of the equipment itself, weight of the grain flour and forces acting on the frame. The equipment has a frame of overall dimensions $600 \mathrm{~mm} \times 725 \mathrm{~mm} \times 1100 \mathrm{~mm}$, fabricated from mild steel angles of $37.5 \mathrm{~mm} \times$ $37.5 \mathrm{~mm} \times 5.5 \mathrm{~mm}$.

\section{Materials and Methods}

Preliminary tests were conducted to find the required rotational speed (rpm) to mix flour in the blender and it was found that the required rotational speed of the blender was $51 \mathrm{rpm}$. Pulleys were selected accordingly to obtain the above rpm for the blender by considering the rpm of the motor. Blender was operated with a 3hp motor. The blender was tested by blending rice flour and wheat flour to the ratio of 3:7, which is generally used as a mixture for preparing bread. The capacity of the blender was $50 \mathrm{~kg}$ per batch. $35 \mathrm{~kg}$ of wheat flour and $15 \mathrm{~kg}$ of rice flour were put into the blender and blending was done with different time periods (1 $\mathrm{min}, 2 \mathrm{~min}, 3 \mathrm{~min}$ and $4 \mathrm{~min}$ ) and three replicates with each batch.

The performance of the blending equipment was evaluated with regard to the time required for blending to give a uniform mixture. The uniformity of the blended mixture was evaluated with gluten content and particle size distributions. Four samples were taken from four different places in the blender to find the uniformity in each trial. Determination of Gluten [5] was done by following SLS method. Particle size distributions were measured by using the impact laboratory test sieve shaker

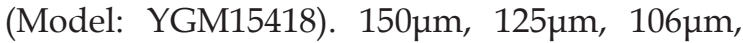
$90 \mu \mathrm{m}$ and $75 \mu \mathrm{m}$ sieves were fixed to the sieve shaker. A sample of $200 \mathrm{~g}$ was put to the sieve shaker and it was operated for 20 minutes. Particle size distribution was calculated by measuring weight of the materials retained in each sieves.

Data obtained for gluten content and particles size distributions were subjected to analysis of variance (ANOVA) using AgRes statistical package for windows version 3.01. Completely randomized design (CRD) was used to evaluate the data and mean comparisons were done by using least significant difference test.

\section{Results and Discussion}

Table 1 shows the gluten content at different places of flour mixture with mixing time. Data were statistically analyzed and the analysis has shown that the gluten content is significantly different when mixing times are 1 and 2 minutes and it is not significantly different when mixing time is 3 minutes and above. These gluten contents results indicate that the minimum mixing time required to give a uniform flour mixture is 3 minutes.

Table 2 shows the percentage particle size distribution at different places of flour mixture with mixing time. Data were statistically analyzed and the analysis has shown that the percentage particle size distribution is significantly different when mixing times are 1 and 2 minutes and it is not significantly different when mixing time is 3 minutes and above. These results indicate that the minimum mixing time required to give a uniform flour mixture is 3 minutes.

Table 1 - Gluten content at different places of flour mixtures with mixing time

\begin{tabular}{|c|c|c|c|c|}
\hline \multirow{2}{*}{$\begin{array}{c}\text { Mixing } \\
\text { time } \\
\text { (Min.) }\end{array}$} & \multicolumn{5}{|c|}{$\begin{array}{c}\text { Gluten \% (Dry basis) at different } \\
\text { places }\end{array}$} \\
\cline { 2 - 5 } 1 & $\mathrm{~A}$ & $\mathrm{~B}$ & $\mathrm{C}$ & $\mathrm{D}$ \\
\hline 1 & $9.41^{\mathrm{b}}$ & $10.31^{\mathrm{a}}$ & $9.41^{\mathrm{b}}$ & $8.82^{\mathrm{c}}$ \\
\hline 2 & $9.54^{\mathrm{b}}$ & $9.45^{\mathrm{b}}$ & $8.1^{\mathrm{c}}$ & $9.9^{\mathrm{a}}$ \\
\hline \multicolumn{5}{|c|}{} \\
\hline 3 & $9.41^{\mathrm{a}}$ & $9.38^{\mathrm{a}}$ & $9.42^{\mathrm{a}}$ & $9.39^{\mathrm{a}}$ \\
\hline 4 & $9.45^{\mathrm{a}}$ & $9.45^{\mathrm{a}}$ & $9.44^{\mathrm{a}}$ & $9.36^{\mathrm{a}}$ \\
\hline
\end{tabular}

Values followed by different letter within row for each mixing time are significantly different at $p<0.05$, according to least significant difference test.

Above results for gluten contents and percentage particle size distributions at different places of flour mixture indicate that the minimum blending time required to give a uniform flour mixture is 3 minutes. 
Table 2 - Percentage particle size distribution at different places of flour mixtures with mixing time

\begin{tabular}{|c|c|c|c|c|c|c|c|}
\hline \multirow{2}{*}{$\begin{array}{l}\text { Mixing time } \\
\text { (Min.) }\end{array}$} & \multirow{2}{*}{ Place } & \multicolumn{6}{|c|}{ Particle size distribution (\%) } \\
\hline & & $>150 \mu \mathrm{m}$ & $150-25 \mu \mathrm{m}$ & $125-06 \mu \mathrm{m}$ & $106-0 \mu \mathrm{m}$ & $90-5 \mu \mathrm{m}$ & $75 \mu \mathrm{m}<$ \\
\hline \multirow{4}{*}{1} & A & $30.68^{c}$ & $56.97^{\mathrm{b}}$ & $9.98^{\mathrm{a}}$ & $2.12^{\mathrm{a}}$ & $0.02^{\mathrm{c}}$ & $0.23^{\mathrm{b}}$ \\
\hline & B & $26.87^{\mathrm{d}}$ & $69.45^{\mathrm{a}}$ & $3.38^{\mathrm{b}}$ & $0.23^{\mathrm{b}}$ & $0.03^{\mathrm{b}}$ & $0.04^{\mathrm{c}}$ \\
\hline & $\mathrm{C}$ & $43.19^{b}$ & $52.98^{\mathrm{c}}$ & $3.03^{c}$ & $0.27^{\mathrm{b}}$ & $0.03^{\mathrm{b}}$ & $0.5^{\mathrm{a}}$ \\
\hline & $\mathrm{D}$ & $46.94^{\mathrm{a}}$ & $50.06^{c}$ & $2.69^{\mathrm{d}}$ & $0.16^{\mathrm{c}}$ & $0.04^{\mathrm{a}}$ & $0.11^{\mathrm{b}}$ \\
\hline \multirow{4}{*}{2} & A & $28.85^{\mathrm{b}}$ & $60.39^{\mathrm{d}}$ & $7.4^{\mathrm{a}}$ & $2.45^{\mathrm{a}}$ & $0.5^{\mathrm{b}}$ & $0.41^{\mathrm{b}}$ \\
\hline & $\mathrm{B}$ & $26.67^{\mathrm{d}}$ & $64.26^{\mathrm{b}}$ & $6.34^{\mathrm{b}}$ & $1.8^{\mathrm{b}}$ & $0.47^{\mathrm{b}}$ & $0.46^{\mathrm{a}}$ \\
\hline & C & $27.92^{\mathrm{C}}$ & $62.34^{\mathrm{c}}$ & $6.38^{\mathrm{c}}$ & $2.43^{\mathrm{a}}$ & $0.57^{\mathrm{a}}$ & $0.36^{\mathrm{d}}$ \\
\hline & $\mathrm{D}$ & $30.01^{\mathrm{a}}$ & $65.63^{\mathrm{a}}$ & $2.33^{\mathrm{c}}$ & $1.36^{\mathrm{c}}$ & $0.28^{\mathrm{c}}$ & $0.39^{c}$ \\
\hline \multirow{4}{*}{3} & A & $27.45^{\mathrm{a}}$ & $65.31^{\mathrm{a}}$ & $5.07^{\mathrm{a}}$ & $1.13^{\mathrm{a}}$ & $0.54^{\mathrm{a}}$ & $0.5^{\mathrm{a}}$ \\
\hline & B & $27.41^{\mathrm{a}}$ & $65.32^{\mathrm{a}}$ & $5.08^{\mathrm{a}}$ & $1.15^{\mathrm{a}}$ & $0.53^{\mathrm{a}}$ & $0.51^{\mathrm{a}}$ \\
\hline & $C$ & $27.4^{\mathrm{a}}$ & $65.35^{\mathrm{a}}$ & $5.06^{\mathrm{a}}$ & $1.16^{\mathrm{a}}$ & $0.52^{\mathrm{a}}$ & $0.51^{\mathrm{a}}$ \\
\hline & $\mathrm{D}$ & $27.42^{\mathrm{a}}$ & $65.3^{\mathrm{a}}$ & $5.1^{\mathrm{a}}$ & $1.17^{\mathrm{a}}$ & $0.51^{\mathrm{a}}$ & $0.5^{\mathrm{a}}$ \\
\hline \multirow{4}{*}{4} & A & $27.46^{\mathrm{a}}$ & $65.32^{\mathrm{a}}$ & $5.09^{\mathrm{a}}$ & $1.14^{\mathrm{a}}$ & $0.5^{\mathrm{a}}$ & $0.49^{\mathrm{a}}$ \\
\hline & B & $27.4^{\mathrm{a}}$ & $65.33^{\mathrm{a}}$ & $5.1^{\mathrm{a}}$ & $1.15^{\mathrm{a}}$ & $0.54^{\mathrm{a}}$ & $0.48^{\mathrm{a}}$ \\
\hline & $C$ & $27.43^{\mathrm{a}}$ & $65.35^{\mathrm{a}}$ & $5.02^{\mathrm{a}}$ & $1.18^{\mathrm{a}}$ & $0.52^{\mathrm{a}}$ & $0.5^{\mathrm{a}}$ \\
\hline & $\mathrm{D}$ & $27.45^{\mathrm{a}}$ & $65.29^{\mathrm{a}}$ & $5.04^{\mathrm{a}}$ & $1.13^{\mathrm{a}}$ & $0.57^{\mathrm{a}}$ & $0.52^{\mathrm{a}}$ \\
\hline
\end{tabular}

Fabrication cost for the developed flour blender was about 100,000 SLR and flour blending cost was 0.97 SLR per $\mathrm{kg}$. When the developed flour blender is compared with the available blending machines in the international market with same capacity, developed flour blender has reduced the blending time and the initial cost of the machine by 5 times while the flour blending cost is reduced by $25 \%$.

\section{Conclusion}

Based on the results of gluten content and percentage particle size distribution at different places of flour mixture, it can be concluded that the minimum mixing time required to give a uniform flour mixture is 3 minutes.

\section{Acknowledgements}

Authors wish to express their gratitude to WELDISI PVT LTD, Lunama, Ambalanthota for providing funds for carrying out this research project.

\section{References}

1. Fitzpatrick, J. J., Particulate and powder mixing, Food mixing, $1^{\text {st }}$ ed, Blackwell Publishing Ltd, United Kingdom, 2009, 269 p.

2. Khurmi, R. S., Gupta, J. K., A Text Book of Machine Design, 2nd ed., Eurasia Publishing, New Delhi, 1993. pp. 614-625.

3. Kazembe, H. W., Approaches to Successful Development of Low-Cost Fruit Juice Extraction Technologies: A Case Study to Improved Rural Livelihood in Malawi. Tropentag, Stuttgart-Hohenheim, 2005, 3 p.

4. Deveswaran, R., Bharath, S., Basavaraj, B. V., Abraham, S., Furtado, S., \& Madhavan, V., "Concepts and Techniques of Pharmaceutical Powder Mixing Process" Research J. Pharm. and Tech, M.S Ramaiah College of Pharmacy, MSR Nagar, India Vol.2 (2), April-June, 2009,pp. 245-249.

5. SLS 144, Determination of Gluten., Sri Lanka Standard Specification for wheat flour, $1^{\text {st }}$ Rev., SLS, Sri Lanka, 2003, 10 p. 